\title{
Environmentally-Conscious Supply Chain Design in Support of Food Security
}

\author{
Caroline C. Krejci \\ Department of Industrial and Systems Engineering, University of Washington \\ Box 352650, Seattle, WA USA 98195 \\ E-mail: ckrejci@u.washington.edu \\ Benita M. Beamon \\ Department of Industrial and Systems Engineering, University of Washington \\ Box 352650, Seattle, WA USA 98195 \\ E-mail: Benita@u.washington.edu
}

\begin{abstract}
This paper seeks to design food supply chain structures that can provide food security for every person in the world while supporting long-term environmental sustainability. In particular, we provide alternatives to the current food supply chain structure and analyze their potential for providing food security, in terms of productive capacity and long-term environmental sustainability. Given the current world population and expected continued growth, our analysis suggests that environmentally-sustainable food supply chains would be most effectively supported by local and organic agriculture, while maintaining a parallel industrial agricultural system. This hybrid system would adopt environmentally-sustainable principles whenever possible, seeking to increase reliance on renewable inputs, reduce toxic outputs and maintain biodiversity.
\end{abstract}

Keywords: : agriculture, sustainability, supply chains, food production, farming

\section{Introduction}

There are now more than one billion undernourished people worldwide, and almost all of them live in developing countries (FAO, 2009). This makes hunger and malnutrition the number one risk to global health greater than AIDS, malaria and tuberculosis combined (http://www.wfp.org/hunger/faqs). This condition, termed "food insecurity," is a humanitarian crisis compounded by imminent population growth. The global population is expected to increase from the current 6.8 billion to 9.1 billion by the year 2050, with the most significant growth occurring in developing countries (United Nations, 2009). Providing food security in the face of this rapid expansion will require that food production throughout the world increase at a greater rate than ever before (Pimentel and Pimentel, 2008; Pretty, 2008). The resources required to provide food security for more than 9 billion people are enormous, and some of these resources, such as water, are already scarce in many parts of the world (Parry, 1990; Pimentel and Pimentel, 2008). The question that

* Corresponding Author 
must urgently be answered is: how can we achieve and maintain sustainable food security for our growing population?

Achieving long-term sustainability of a highly productive food supply chain is a multifaceted problem, comprised of economic, social, and environmental elements. Economic performance has been the traditional focus for many supply chains, including the food supply chain (Aramyan et al., 2007; Beamon, 1999). A sustainable food supply chain also is inherently socially beneficial (Hoffman, 2007). In this paper we focus specifically on the impact of environmentally-sustainable practices on food supply chain performance. As an asset for food production, the environment provides many necessary inputs (Pretty, 2008), including soil nutrients. Environmentally-sustainable practices help maintain the quality of these inputs, thereby supporting the long-term productivity and resilience of the food supply chain. Therefore, sustainable long-term food security depends on the food supply chain's ability to indefinitely protect its natural environment and enhance its inputs, as well as its ability to produce sufficient output.

Existing literature in supply chain sustainability focuses primarily on product take-back structures and mechanisms within the domain of durable good supply chains. The focus of this paper is on food, a consumable good with unique characteristics; namely, that the product of the food supply chain is a necessity for human survival, and that this type of supply chain faces unusually significant political and social challenges. In this paper, we synthesize the existing food supply chain literature and extend previous work in supply chain sustainability, in an effort to design environmentally-conscious food supply chain structures that provide food security. Finally, we provide alternatives to the current food supply chain structure and discuss each alternative's potential for providing food security, in terms of productive capacity and long-term environmental sustainability.

\section{Toward a Sustainable Food Supply Chain}

Achieving food security is a complex problem that depends upon the success of multiple interacting components, as shown in Figure 1. The four elements that directly support food security are availability, diversity, safety, and equity. In this context, availability is the physical availability of food to consumers, which is made possible by sufficient food production capacity and a distribution network that successfully delivers food to consumers. Diversity refers to nutritional diversity and biodiversity. Food safety is the absence of foodborne illness, and equity includes fairness in food allocation and affordability.

Inequitable food supply is a serious obstacle to food security. The FAO reports that food insecurity has been steadily increasing in severity over the past ten years, despite sufficient global food production (FAO, 2009). In fact, there is enough food produced in the world right now to feed every person, but even so, every five seconds a child dies from hunger (FAO, 2004a; http://www.wfp.org/hunger/faqs). As a result of poverty, inadequate infrastructure, and trade policy, many people lack economic or physical access to food. Often, these existing problems are exacerbated by severe disruptions in food supply chains, caused by natural and human-caused disasters, such as war and drought. Although food equity is a critical component of food security, it is not directly related to environmental sustainability. To adequately address food equity would require an extensively detailed discussion that would go beyond the scope of this paper.

The three remaining components that directly support long-term food security (availability, diversity and safety) are all underpinned by environmentallysustainable practices. In particular, healthy environmental inputs are essential to maintaining long-term food production capacity. Additionally, environmentally-sustainable practices support and are supported by biodiversity, which in turn enables the nutritional diversity that is necessary in foodsecure diets. Food safety is an ancillary benefit of environmentally-sustainable food production methods, resulting from minimal use of toxic inputs and less-intensive livestock production practices.

Environmentally-sustainable practices require nontoxic and regenerative inputs and outputs. Therefore, in assessing the degree to which a food supply chain can support food security, it is necessary to evaluate its inputs and outputs in terms of these 
Figure 1. The role of environmentally-sustainable production \& distribution

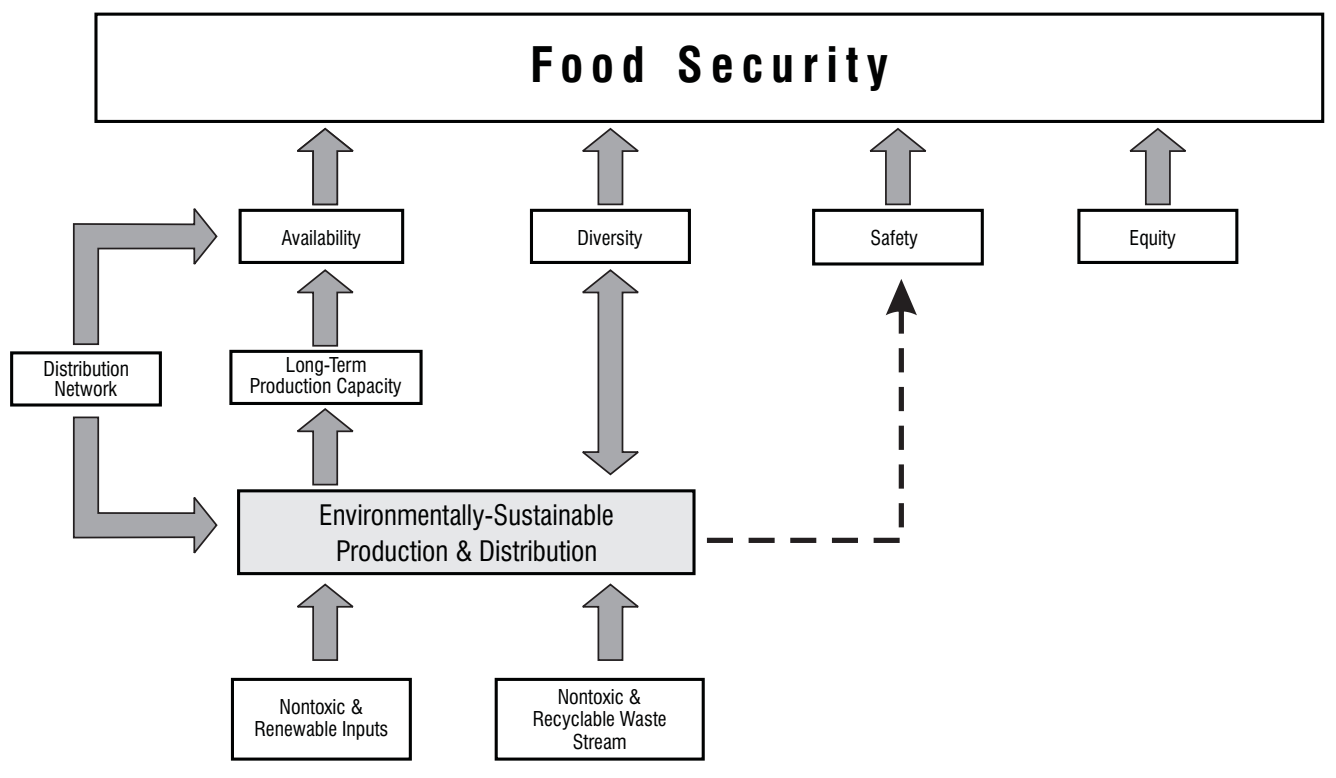

qualities. Figure 2 shows the basic structure of the modern industrial food supply chain. It is important to note that not every food supply chain contains all of these elements. For example, agrochemical suppliers are not present in some types of food chains, while they are a primary component of other types. However, all food chains share a common basic structure with the following elements: inputs and input suppliers, producers, consumable outputs, consumers, and a waste stream. While the supply chain in Figure 2 represents a system with the capacity to support food security in the short term, many characteristics of its structure pose serious problems for environmental sustainability and therefore for long-term food security. In particular, this supply chain is characterized by inputs that are non-renewable and/or toxic, processes that use these inputs inefficiently, and a waste stream that is damaging to natural food production inputs and the surrounding ecosystem.

The essential elements of an environmentallysustainable food supply chain are given in Table 1 . Next, we will discuss each of these elements and provide examples that illustrate how these characteristics are working to support food security, while safeguarding the environment.

\subsection{Energy}

Independence from oil and other nonrenewable fossil fuels as energy sources is a key characteristic of an environmentally-sustainable food system. Frumkin $e t$ al. (2009) suggest that because industrialized food production is highly sensitive to petroleum prices and availability, food insecurity among people with fewer resources may increase as oil becomes less affordable and/or available. In contrast, food production systems that do not rely heavily on agrochemicals, mechanization and long-distance transport are likely to be resilient to petroleum scarcity. An example of such a system is that of Cuba, which lost significant access to subsidized petroleum and agrochemical imports after the Soviet Union collapsed. In response, Cuba adapted its inputs, production methods and distribution network to create a self-sustaining local food system. In this case, the successful adaptation of the food system was guided by the government, which promoted urban farming and changed its policies to reduce centralized price controls (Rosset, 2000). Another, smaller-scale example of a food system that is almost entirely independent of nonrenewable inputs is the Hockerton Housing Project, a self-sustaining community in the UK (http://www.hockertonhousingproject.org.uk). For the 


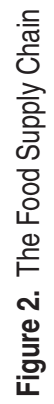

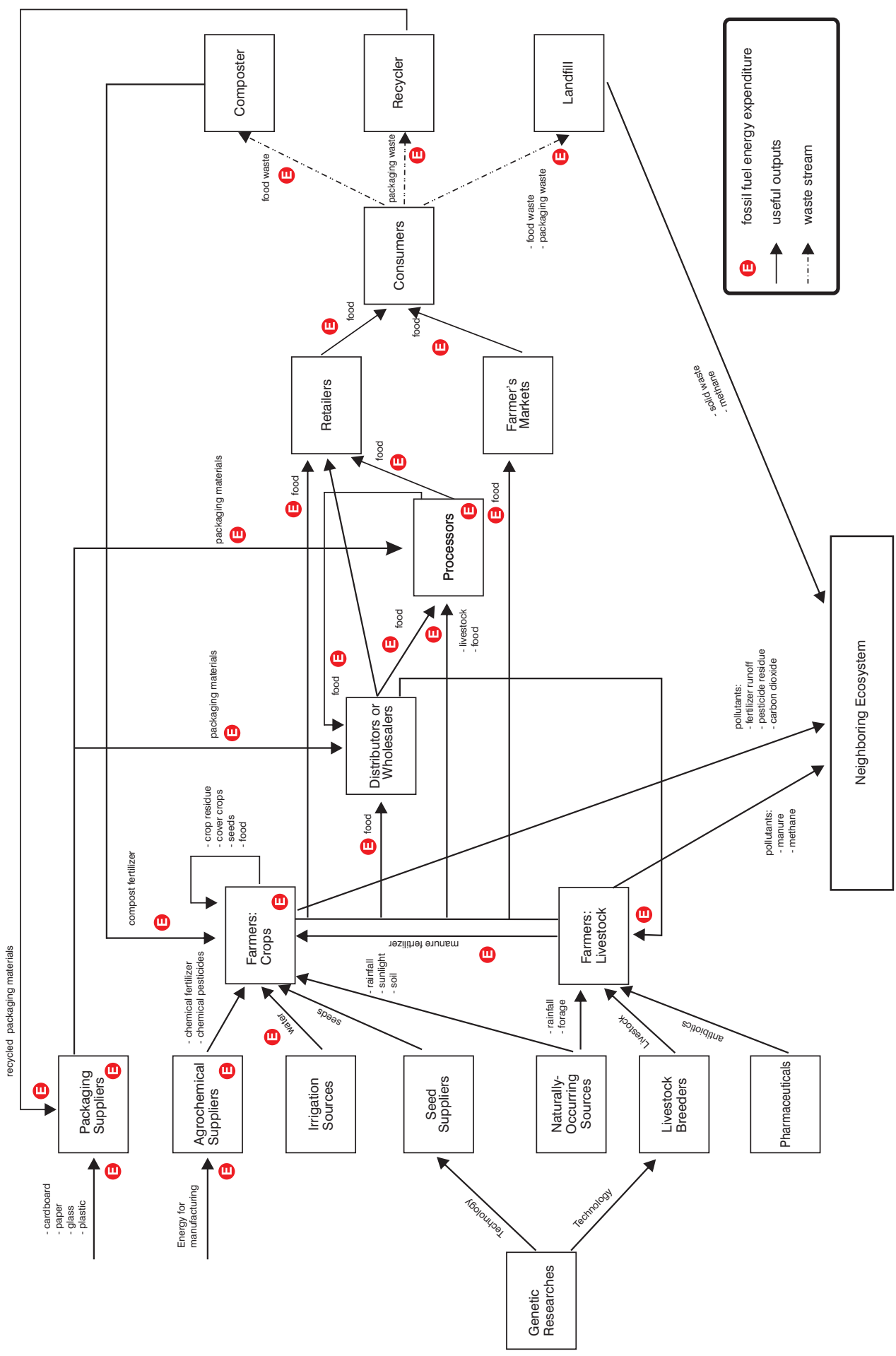


Table 1. Characteristics of environmentally-sustainable food systems

\begin{tabular}{|c|l|}
\hline $\begin{array}{c}\text { Food Supply Chain } \\
\text { Component }\end{array}$ & $\begin{array}{c}\text { Environmentally-Sustainable } \\
\text { System Characteristic }\end{array}$ \\
\hline \multirow{2}{*}{ Energy } & Independent from nonrenewable inputs \\
\cline { 2 - 2 } & No net greenhouse gas emissions \\
\hline \multirow{2}{*}{ Water } & Water utilization is balanced with supply \\
\hline \multirow{2}{*}{ Soil } & Effective utilization of soil nutrients \\
\cline { 2 - 2 } & No nutrient leaching into waterways \\
\cline { 2 - 2 } & No accumulation of harmful residues in soil \\
\cline { 2 - 2 } & No net topsoil erosion \\
\hline $\begin{array}{c}\text { Plants \& } \\
\text { Animals }\end{array}$ & Biodiversity is maintained \\
\hline $\begin{array}{c}\text { Knowledge \& } \\
\text { Practices }\end{array}$ & $\begin{array}{l}\text { System makes productive use of the } \\
\text { knowledge and skills of farmers }\end{array}$ \\
\hline
\end{tabular}

community to remain self-sustaining, tenants must accept a lifestyle that includes limiting their diets to seasonal foods and committing to producing food communally (Sassi, 2006).

Another characteristic of an environmentallysustainable food system is one in which there are no net greenhouse gas emissions. Emissions are created when fossil fuels are burned for energy, which occurs both directly (during mechanization and transport) and indirectly (during the energy-intensive manufacture of fertilizers and pesticides) in most modern food systems. Significant quantities of greenhouse gases are also released from tilled soils (Merrington et al., 2002). Producing greenhouse gases at rates greater than environmental absorption rates leads to climate change, which is predicted to undercut food system productivity in the long term, particularly in the regions of the world with the greatest vulnerability to food insecurity (Gregory et al., 2005; Parry, 1990). However, the choice of production and distribution methods can make a difference in a food system's contribution to greenhouse gas emissions. Through the use of life cycle assessment, Sim et al. (2007) show that food supply chains that include minimal transport, packaging and storage, and those that use organic fertilizers have a significantly lower impact on global warming than systems that do not have these characteristics. In this study, it was shown that avoiding the use of air freight to transport foods to consumers is the most significant factor in minimizing food supply chain impact on global warming. However, it was also noted that eliminating distant transport of food can impact consumers' food choices. Pretty (2008) also emphasizes the potential of sequestering carbon dioxide in topsoil and plants as a method for reducing or eliminating net greenhouse gas emissions, citing a study in which 286 agricultural carbon sequestration projects successfully sequestered 11.4 Mt C per year on $37 \mathrm{Mha}$. He provides a comprehensive list of mechanisms for increasing carbon sinks and reducing greenhouse gas emissions in agricultural systems, with conservation tillage being one of the most effective mechanisms.

\subsection{Water}

The most significant impact of climate change on food systems will be on water availability, which will likely be reduced in many areas in the world through changes in rainfall patterns and increased evapotranspiration (Parry, 1990). The supply of water to agricultural systems is not only threatened by reduced rainfall as a consequence of climate change and global warming, but also by over-consumption (Pimentel and Pimentel, 2008). Sustainable food systems must make effective use of water by maintaining the quantity and quality of the water supply. In terms of water quantity, a sustainable system will balance water usage with available supply. A system can attain this characteristic by growing crops suited to the local environment or through rainfed crop breeding. These practices reduce the need for irrigation systems by relying on natural rainfall as a primary source of water. Reduced reliance on irrigation also benefits sustainability in terms of reduced fossil fuel consumption, because fossil fuels are commonly used as a source of energy to power water pumps and transportation from water sources to farms (Pimentel and Pimentel, 2008). Rosegrant and Cline (2003) indicate that water harvesting trials in some African countries increased productive yields by a factor of two to three, without depleting groundwater sources. However, successful water harvesting requires that farmers are educated in these techniques, that there is sufficient rainfall to harvest, and that appropriate water harvesting technology is available 
(Rosegrant and Cline, 2003). Balancing water usage and supply is particularly difficult in arid regions, but Maretzki and Tuckermanty (2008) suggest that it is possible for desert agriculture to be productive without stressing the water supply. For example, the people of the Tohono O'odham Reservation in Sells, Arizona, are regenerating the use of traditional dry land agriculture to build a healthier and self-sustaining food supply. For this system to work, farmers must acquire the necessary knowledge to support these techniques, and consumers must be willing to accept a range of food limited to what the local conditions will support. Efficient irrigation technologies can also help to increase productivity with a limited water supply. For example, precision irrigation, soil-moisture monitoring and laser-leveling of fields have the potential to double the productivity per unit of water for many crops (Gleick, 2002). In fact, shifting from conventional surface irrigation to drip irrigation in India has increased overall water productivity by $45-255 \%$ (Gleick, 2002).

\subsection{Soil}

Maintaining soil quality without endangering the surrounding ecosystem is another characteristic of sustainable food systems. An important contributor to soil quality is the effective utilization of soil nutrients, which can be accomplished by training farmers to use planning and assessment tools for integrated nutrient management (Andersson et al., 2005; Merrington et al., 2002). In this way, farmers learn to time the release of nitrogen from fertilizer to match crops' demand, thereby preventing excess nitrogen from leaching into neighboring waterways (Merrington et al., 2002). Andersson et al. (2005) also describe a tool that farmers can use to help them effectively manage phosphorus application to their fields, as well as a model for the assessment of nutrient flows that can help to identify depletion of essential nutrients Another food system characteristic that supports soil quality is the prevention of harmful residue accumulation in the soil (Pimentel and Pimentel, 2008). One way to accomplish this is through organic farming (in which conventional chemical pesticides are not used), or sustainable farming (in which small quantities of chemical pesticides are typically used). The avoidance of conventional pesticides does not necessarily result in diminished output (Pimentel et al., 2005; Pimentel and
Pimentel, 2008; Pretty, 2008). On the contrary, a study of 62 integrated pest management initiatives in 26 industrialized and developing countries shows that more than $60 \%$ of these projects experienced significant yield increases, while substantially reducing chemical pesticide usage (Pretty and Waibel, 2005; Pretty, 2008). Pretty (2008) attributes these results not only to the effectiveness of integrated pest management, but also to farmer training and education in other related sustainable agronomic practices. A third practice that supports soil quality is the management of topsoil erosion (Pimentel and Pimentel, 2008; Pretty, 2008; Weis, 2007). Zero-tillage systems, planting cover crops on fallow fields, and agroforestry can be effective methods of slowing erosion (Lal, 1998; Merrington, et al., 2002; Morgan, 1995; Pretty, 2008). Reporting on the results of a program to implement improved agricultural practices in Ghana, Boahen et al. (2007) indicated that 15 of 21 communities participating in the program reported reduced soil erosion as a result of reducing or eliminating tillage. They noted, however, that planting crops through untilled soil was more difficult and required that farmers be equipped with the appropriate tools and the knowledge of how to use them effectively.

\subsection{Plants and Animals}

The sustainability of a food supply chain also depends on the types of food plants and animals that are raised. Biodiversity is a fundamental characteristic of food system sustainability (FAO, 2004b; Pimentel and Pimentel, 2008). It can be measured in terms of the variety of plants and animals that are produced, and also by the variety of other organisms that inhabit the ecosystem of which the crops and livestock are a part. Because modern agriculture has encouraged many farmers to adopt uniform high-yielding types of plants or animals, many varieties and breeds of food plants and animals have been allowed to disappear (Thrupp, 2000). People depend on just 14 mammal and bird species for $90 \%$ of their food supply from animals, and only four species - wheat, maize, rice and potatoes provide half of the human population's plant-based caloric intake (FAO, 2004b). The FAO also estimates that approximately $75 \%$ of the genetic diversity of agricultural crops has been lost over the last century 
(FAO, 2004b). This is a potentially dangerous situation, because the unique characteristics of a diverse plant and animal population enable them to more effectively survive changes in climate and to ward off disease (FAO, 2004b). Consumers also benefit from a wide variety of foods, which supports human health (Thrupp, 2000). An example of a food system in the United States that maintains crop and livestock diversity is that of the Amish (Blake et al., 1997). It is likely that Amish food production is biodiverse because the Amish farmers produce food not only for market, but also to sustain their own communities.

The FAO biodiversity report (2004b) cites multiple examples of regulations that have been enacted to protect biodiversity, including the 2004 International Treaty on Plant Genetic Resources for Food and Agriculture, which was established to ensure that plant genetic resources are conserved and sustainably used, and that the benefits from their use are equitably distributed. Environmentally-sustainable farms must also maintain the biodiversity of the ecosystem within and surrounding farms, in order to preserve soil quality, enable pollination and reduce erosion (Merrington, et al., 2002; Pimentel and Pimentel, 2008; Pretty, 2008; Thrupp, 2000). Allowing natural predators to exist on farms reduces the need for petroleum-based pesticides, which not only helps to support environmental health, but can also be a costeffective pest management strategy (Luna and House, 1990).

\subsection{Knowledge and Practices}

Farmers' knowledge of sustainable production practices and willingness to use them constitute another key characteristic of an environmentallysustainable food system. For example, tools for maintaining soil quality, methods of integrated pest management, and efficient water usage must be taught to farmers before they can be put into practice. Pretty (2008) argues that a lack of information and management skills is a major barrier to the adoption of sustainable practices. To combat this problem, farmers could be encouraged to attend training courses and demonstrations, to seek assistance from farming advisors and to learn for themselves (Ingram, 2008). Other factors that influence success in adopting environmentally-sustainable practices include a farmer's personal value system, as well as consumer demands for sustainably produced food. Selfa et al. (2008) suggest that a closer relationship between producers and consumers could help to encourage farmers to use environmentally-friendly production practices. Direct distribution methods, such as farmers' markets and CSAs, offer potential avenues toward building such relationships.

\section{Designing an Environmentally- Sustainable Food Supply Chain}

Given the aforementioned characteristics of environmentally-sustainable food systems, the next step is to design a food supply chain that is fully sustainable in the long term and provides food security for every person in the world. With such a vast array of inputs, processes and outputs, as well as environmental and socio-political variables, it is possible that no such universal structure actually exists. However, it is useful to synthesize the discussion of food supply chain sustainability and envision environmentally-sustainable structures.

The structure of a fully sustainable food supply chain greatly depends upon the size of the population it serves. The larger the population, the more difficult it is to design a food system that both satisfies food security and does not exceed the production capacity of the planet. For example, a hunter/gatherer food system adequately provided food security for a relatively small ancient population. However, it is extremely unlikely that this system alone could meet the needs of today's much larger global population. Naturally-occurring food sources would be quickly exhausted and would be unable to generate food reliably and in sufficient quantities to sustain the current population.

Therefore, our analysis of environmentallysustainable food supply networks is categorized on the basis of output, satisfying low, medium and high demand requirements. The structures of these networks are illustrated in Figures 3, 4 and 5, respectively. While in reality food supply chains are highly complex and contain a multitude of inputs, processes, distribution methods and outputs, these figures are intended to characterize core supply chain structures, and therefore contain only the components 
that are central to each network. For example, the low and medium-demand supply chains (Figures 3 and 4) are portrayed as entirely closed-loop, self-sustaining systems. In reality, a minimal amount of waste would enter the neighboring ecosystem, and farms would require some inputs that are not self-generated.

\subsection{Level 1 System: Local/civic agriculture with reserve regional/global agriculture support}

Achieving an environmentally-sustainable food system that can satisfy a low level of demand is greatly simplified by the ability to nearly eliminate reliance on fossil fuels. The enormous productive capacity of oilsustained industrial agriculture would no longer be necessary, and as a result, the complications that oil creates for sustainability, in terms of eventual supply depletion and greenhouse gas emissions, would be greatly reduced. Figure 3 illustrates a sustainable food supply chain in a low demand environment. This system is predominantly based on local/civic agriculture, the success of which depends upon the geographic dispersion of the population. However, a system based strictly on local production and distribution is risky, even for small populations. Unpredictable ecological variables, such as weather and pests, can threaten local food systems. Therefore, a secondary regional and global system would be necessary to ensure consistent long-term availability and food security. For regions that are unable to maintain year-round production, reliance on such a secondary system would likely be greater. This secondary system would at least minimally rely on fossil fuels for long-distance transport.

The text box in Figure 3 lists the key characteristics of the system, identifying the characteristics that differ from those of the current industrial supply chain (Figure 2). The most apparent overall difference between the current food supply chain and an environmentally-sustainable, low-demand version is a significant reduction in size and complexity. The network in Figure 3 includes far fewer inputs into the farming process than the system in Figure 2. Most notably, neither agrochemicals nor antibiotics appear as inputs. Agrochemicals are replaced by natural fertilizers and integrated pest management techniques, enabling fully organic production. In the case of low demand, the lower yields associated with organic production are sufficient to provide food security for the entire population. These practices, along with soil maintenance strategies such as nutrient management and low- or no-till techniques, would ensure healthy and productive soil and minimal topsoil erosion, which are critical to environmental sustainability.

A moderate amount of irrigation would still be necessary to support crop production, particularly in periods of low rainfall. However, reliance on fossil fuels to pump and transport water from underground sources would be minimal. Instead, the system would source water primarily from previously collected rainfall and from nearby rivers and lakes, with supplementary underground water supplied by windpowered pumps. These irrigation methods would be sufficient to provide food security for a low-demand food supply chain, particularly if they were applied in conjunction with regionally appropriate crop choices. In addition to a reduced reliance on fossil fuels, these low-intensity water harvesting techniques would be more environmentally-sustainable than current methods, because they would not deplete underground water tables more quickly than they could be replenished.

In addition to fewer inputs, the food production stage of the low-demand food supply chain in Figure 3 differs from the current food supply chain. Rather than consisting of farms that specialize in the production of a single crop or livestock type, a more sustainable system would be based on self-sustaining and biologically diverse farms. Farms that raised livestock would also grow a variety of plant crops, some of which would provide supplementary feed for the livestock, while manure from the animals would be used to fertilize the crops. Farms producing only plant crops would maintain soil nutrients with composted crop residuals, post-consumer compost, and other naturally available supplements. Farms would also use soil-enhancing techniques, such as rotating crops appropriately and using cover crops to renew the soil. This holistic approach to farming would enable farms to become closed systems, with no waste products entering and harming neighboring ecosystems, and would also potentially allow farms to act as carbon sinks, thereby reducing the impact of global greenhouse gas production on climate change. 


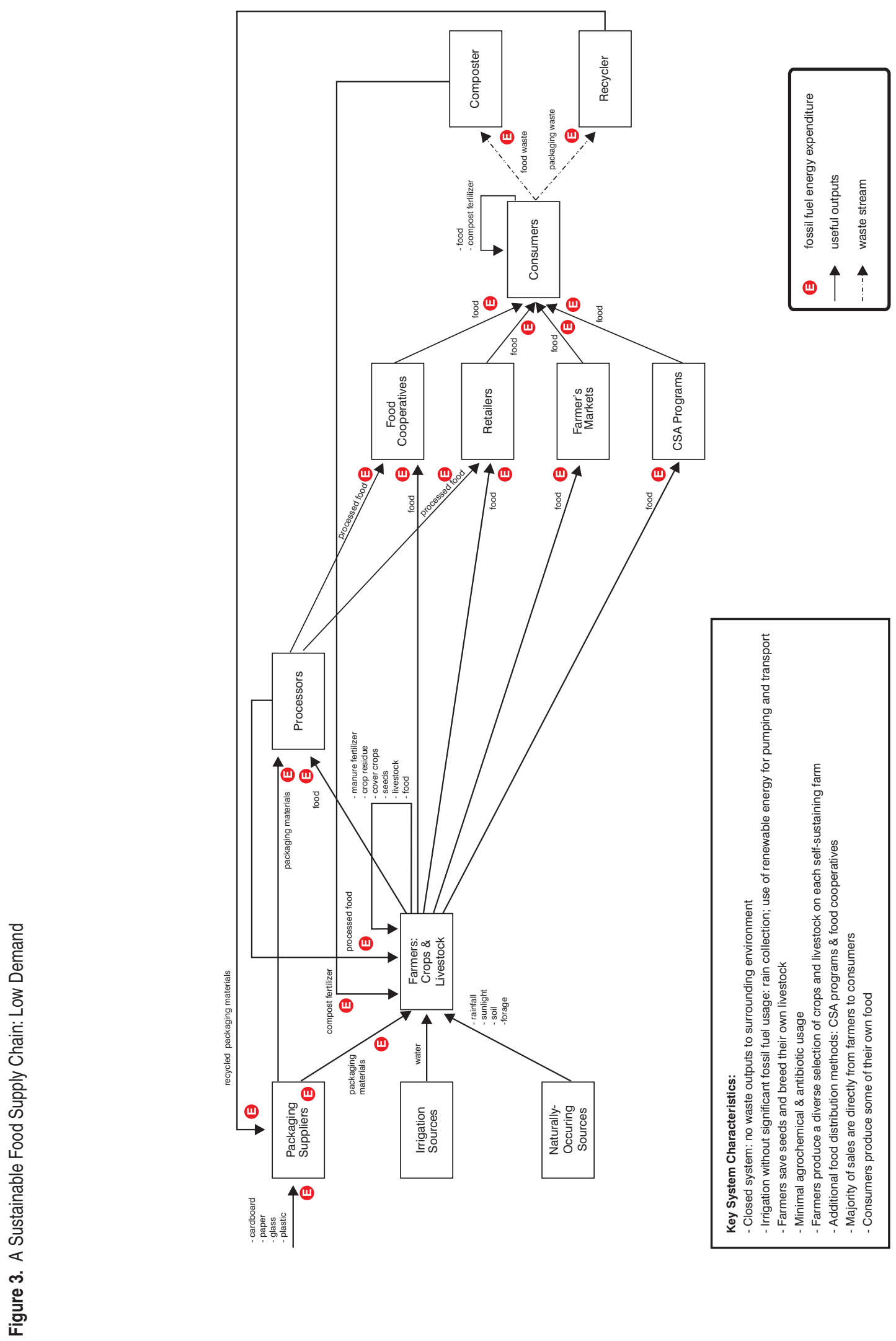


Distribution of food products would also change significantly. With a locally-based agricultural system, consolidation and redistribution would be rendered largely unnecessary, and farmers would primarily sell their products directly to consumers through farmers' markets and CSA programs. Some urban retail operations would exist as well, particularly in the form of food cooperatives.'

Another key characteristic of the environmentallysustainable low-demand food supply chain is consumer behavior. Most importantly, nearly all consumers would be active participants in the supply chain. Consumers would produce significant amounts of their own food, in community and personal gardens. Additionally, direct contact with food producers through farmers' markets and CSA programs would enable consumers to act as partners with farmers, facilitating a dialogue between the two parties and helping to align their goals. Community involvement would ensure that consumers could help to shape the supply chain and gain a better understanding of sustainability issues and the impact of their purchasing decisions. Consumers would also reuse, recycle and compost food waste products, supporting the closedloop structure of the supply chain.

\subsection{Level 2 System: Local/civic agriculture with supplemental regional/global agriculture}

An environmentally-sustainable food system supplying moderate demand would necessarily rely more heavily on industrial agricultural techniques in order to attain sufficient levels of productivity to provide food security for the population. The structure of the supply network would remain primarily based on local production and distribution. However, the regional and global distribution network would become more prominent than in the low-demand system; it would not only be used as a backup in the event of supply chain failures but also as an integral part of the system. The increased demand requirements pose greater challenges to maintaining environmental sustainability and food security, and as a result, some tradeoffs must be made in the near term. For example, some fossil fuels would be necessary at first, but as technology develops, energy requirements would eventually be fulfilled using renewable sources. This development would increase the sustainability of the system.

An environmentally-sustainable moderatedemand food network is given in Figure 4. In comparison with the current food supply chain (Figure $2)$, this system is relatively uncomplicated, and it maintains the self-sufficient, closed-loop structure of the low-demand system. However, several modifications to the low-demand system (Figure 3) have been implemented to increase productive capacity. Agrochemicals have returned to the system as a significant input to the food production process, although in quantities much reduced from a typical industrial system. Because they are used sparingly and judiciously, they produce fewer environmental pollutants. Irrigation must sometimes be supported with fossil fuel energy, due to the system's reliance on production and transportation of underground water sources.

Farms are still primarily holistic, closed-loop systems with primary distribution direct to the consumer through farmers' markets and CSA programs. However, consolidation and redistribution through wholesalers now becomes a significant component of the system, as regional and global distribution become more important. Therefore, food cooperatives and grocery retailers concurrently become more prominent methods of distributing food to consumers. Although this characteristic reduces the amount of direct communication between farmers and consumers somewhat, it streamlines food distribution and thereby potentially reduces greenhouse gas emissions from transport.

\subsection{Level 3 System: Regional/global agriculture with supplemental local/civic agriculture}

Large demand, such as that generated by the current global population, poses the greatest challenge to environmentally-sustainable food supply chain design. To achieve sustainability, such a system would necessarily require a significant reduction in fossil fuel usage, but would still be required to produce adequate

${ }^{1}$ A food cooperative is an autonomous association of consumers that are united voluntarily to meet their common economic, social, and cultural needs through a jointly-owned and democratically-controlled enterprise (www.bloomingfoods.coop). The purchasing decisions of the cooperative are based on members' votes, which enables the community to collectively determine how best to support farmers and consumers. This democratic process is central to maintaining social sustainability in the food supply chain. 


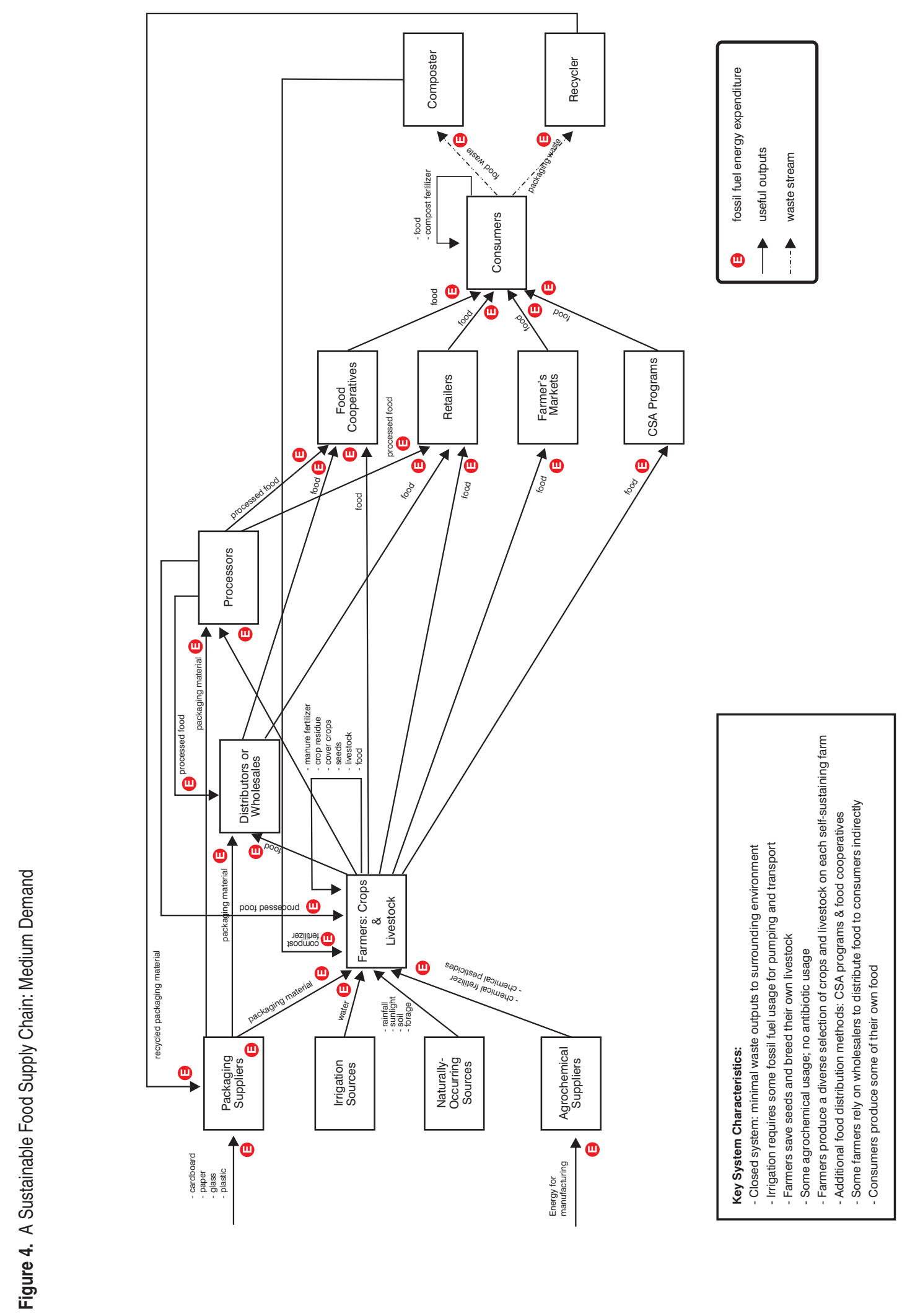


yields to maintain food security. Figure 5 depicts a high-demand structure. In contrast to Figures 3 and 4, which address low and moderate levels of demand, Figure 5 has many inputs, relies upon fossil fuels for agrochemicals and transport, and is not closed-loop. This system shares many structural characteristics with the current food supply chain (Figure 2). However, the new system retains multiple elements that support environmental sustainability. Although regional and global food distribution must now support the supply chain structure, local production and distribution continue to play a significant role, thereby reducing fossil fuel consumption for transport. Farms are no longer completely self-sustaining, relying on outside suppliers for seeds and livestock, and using agrochemicals to a degree that negatively impacts the neighboring ecosystem. Environmental sustainability is vastly improved over the current system, however, with farmers continuously monitoring soil conditions and applying agrochemicals only as needed. Distribution takes on a less personal role, with farmers and consumers separated by distance and consolidation stages in the supply chain. However, food cooperatives enable consumers to influence the food supply chain with their collective purchases. Consumers also continue to positively impact the system's sustainability by producing some of their own food and recycling and composting waste materials.

A principal element of the high-demand food system shown in Figure 5 is a shift toward greater consumption of plant-based products and away from animal-based products. A diet that is primarily plantbased is much less resource-intensive than a diet based on animal products. Pimentel and Pimentel (2008) estimate that 40 million tons of grain protein suitable for human consumption are currently fed to the world's livestock, which could otherwise increase the amount of protein available to human consumers by $34 \%$. Therefore, a predominantly plant-based food supply would reduce output requirements dramatically, while potentially providing an increased level of food security. A change in consumer behavior could be facilitated by governmental support. Most importantly, the current subsidies that support animalbased food production would need to be shifted to support the production of more sustainable food types. As supplies of fossil fuels diminish and population growth increasingly stresses production capacity, governments may begin to direct resources toward the production of plant foods for human consumption.

Dependence on fossil fuels remains an issue for large-scale food production and distribution. Restrictions on transport distances and agrochemical use help by slowing the rate of fossil fuel depletion, but in the end, these strategies simply delay the inevitable. A key element of true sustainability for this system is the parallel development of renewable energy sources, in the hope that these sources can become viable replacements for fossil fuels. Slowing the rate of fossil fuel consumption enough to provide adequate lead time for renewable energy technology development increases the likelihood of this strategy's long-term success.

This structure of a high-demand food supply chain is idealized. The changes to current food supply chains that would be necessary to enable such a structure would be dramatic, involving political, cultural and infrastructural modifications. However, there are elements of this system that could be more readily implemented. Such a system would be primarily supported by local and organic agriculture, while maintaining a parallel industrial agricultural system. The industrial system, however, would adopt sustainable principles whenever possible, seeking to increase reliance on renewable inputs, reduce toxic outputs and maintain biodiversity.

\section{Conclusions and Future Work}

Finding environmentally-sustainable ways to achieve and maintain food security for the rapidly expanding global population is currently the subject of significant research efforts across diverse disciplines. This is certainly a reason for optimism; through these efforts, worldwide hunger and malnutrition could finally be eliminated, and extreme rates of starvation and foodrelated suffering could become a thing of the past. However, much of the previous work focuses on very specific food systems and individual components of food systems. The systems presented in Section 3 of this paper synthesize these concepts to create supply chain structures that provide a comprehensive view of environmental sustainability in food systems that 


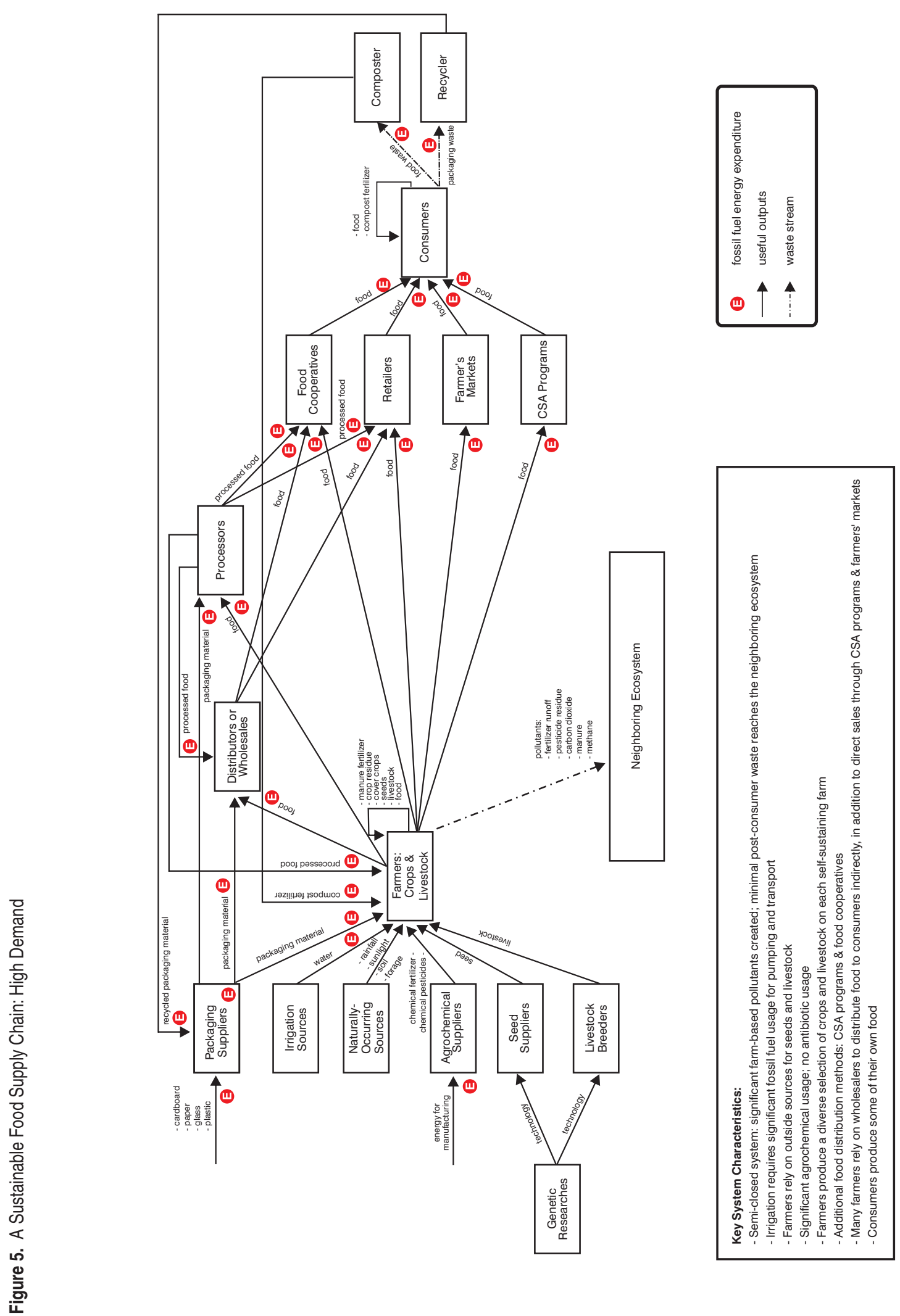


provide food security at low, medium and high levels of demand.

Limiting resource consumption is critical to the sustainability of the food supply chains in Section 3. In particular, the use of sustainable farming practices supports resource conservation. Farmers should be educated in practices such as replacing agrochemicals with natural inputs, reducing irrigation, using conservation tilling practices, and maintaining biodiversity. Ideally, farms should be self-sufficient, relying minimally on outside resources and emitting no harmful waste products into the surrounding environment. A sustainable food supply chain also makes use of a local/civic farming structure, which reduces transport distances and involves greater consumer participation. However, population size and consumer behavior determine the extent to which these methods and structures can be implemented. Given current demand patterns, the food supply chain is necessarily complex, and long-term environmental sustainability is increasingly difficult to maintain. Improvements in renewable energy technology and changes in food consumption patterns, however, would reduce supply chain complexity and improve the chances for long-term success.

The systems presented in Section 3 implicitly identify additional avenues for future research. First, there are issues of practicality. These systems' emphasis upon local and regional distribution may present practical difficulties. Many regions do not have suitable climate conditions to produce adequate quantities of high-quality food year-round, and the foods that can be produced may not be preferred by local consumers. Determining to what degree these regions can and should be supported by distant sources in a sustainable system remains an open question. Additionally, ethical implications arise. What would it cost to develop and operate a fully sustainable food system, and who should pay? Some believe that governments are best equipped to meet this challenge, while others think that local, community-led efforts are the most effective. This question of responsibility leads to perhaps the most difficult and important issue of all: is food security a human right? If so, then providing food security becomes an ethical imperative, rather than a for-profit endeavor. It also seems difficult to square this debate with the ongoing concern of providing farmers and other food supply chain members a living wage. Further complexities arise when the idea of food security as a basic human right is viewed from a global perspective, and it is unclear whether or how this could be resolved politically. However, what is clear is that the creation and implementation of any system that is truly sustainable and eliminates food insecurity will require a coordinated worldwide effort. This means that nations must be willing to operate for the greater international good, in support of the environment and human health.

\section{Acknowledgement}

This work was partly supported by NSF grant CMMI0624219. The authors would also like to thank the anonymous referees for their helpful comments and suggested improvements.

\section{References}

Andersson, R., Algers, B., Bergstrom, L., Lundstrom, K., Nybrant, T., and Sjoden, P. (2005), Food 21: a research program looking for measures and tools to increase food chain sustainability, Ambio 34 (4-5), pp. 275-282.

Aramyan, L.H., Oude Lansink, A.G.J.M., van der Vorst, J.G.A.J., and van Kooten, O. (2007), Performance measurement in agri-food supply chains: a case study, Supply Chain Management: An International Journal 12 (4), pp.304-315.

Beamon, B.M. (1999), Measuring supply chain performance, International Journal of Operations and Production Management 19 (3), pp. 275-292.

Blake, K.V., Cardamone, E.A., Hall, S.D., Harris, G.R., and Moore, S.M. (1997), Modern Amish farming as ecological agriculture, Society and Natural Resources 10 (2), pp. 143160.

Boahen, P., Addo Dartey, B., Delali Dogbe, G., Asare Boadi, E., Triomphe, B., Daamgard-Larsen, S., and Ashburner, J. (2007), Conservation agriculture as practised in Ghana, FAO, Rome, Italy.

FAO (2004a), The state of food security in the world 2004, available at: ftp://ftp.fao.org/docrep/fao/007/y5650e/y5650e00.pdf (accessed 25 August 2009).

FAO (2004b), Biodiversity for food security, available at: http://www.fao.org/docrep/006/y5418e/y5418e00.htm (accessed 29 June 2009). 
FAO (2009), More people than ever are victims of hunger, available at: http://www.fao.org/fileadmin/user_upload/newsroom/docs/ Press\%20release\%20june-en.pdf (accessed 5 August 2009).

Frumkin, H., Hess, J., and Vindigni, S. (2009), Energy and public health: the challenge of peak petroleum, Public Health Reports 124 (1), pp. 5-19.

Gleick, P.H. (2002), Soft water paths, Nature 418 (6896), p. 373.

Gregory, P.J., Ingram, J.S.I., and Brklacich, M. (2005), Climate change and food security, Philosophical Transactions of the Royal Society B 360 (1463), pp. 2139-2148.

Hoffman, M. (2007), The social foundation of sustainable agriculture in southeastern Vermont, Remaking the North American Food System: Strategies for Sustainability, Lyson, T.A. and Hinrichs, C.C. (Eds.), University of Nebraska Press, Lincoln, NE, pp. 315-331.

Ingram, J. (2008), Are farmers in England equipped to meet the knowledge challenge of sustainable soil management? An analysis of farmer and advisor views, Journal of Environmental Management 86 (1), pp. 214-228.

Lal, R. (1998), Soil erosion impact on agronomic productivity and environment quality, Critical Reviews in Plant Sciences 17 (4), pp.319-464.

Luna, J.M and House, G.J. (1990), Pest management in sustainable agricultural systems, Sustainable Agricultural Systems, Edwards, C.A, Lal, R., Madden, P., Miller, R.H., and House, G.J. (Eds.), Soil and Water Conservation Society, Ankeny, IA, pp. 157-173.

Maretzki, A.N. and Tuckermanty, E. (2007), Community food projects and food system sustainability, Remaking the North American Food System: Strategies for Sustainability, Lyson, T.A. and Hinrichs, C.C. (Eds.), University of Nebraska Press, Lincoln, NE, pp. 332-343.

Merrington, G., Winder, L., Parkinson, R., and Redman, M. (2002), Agricultural Pollution: Environmental Problems and Practical Solutions, Spon Press, New York, NY.

Morgan, R.P.C. (1995), Soil Erosion and Conservation, Longman Group, Ltd., Essex, UK.

Parry, M.L. (1990), Climate Change and World Agriculture, Earthscan Publications, Ltd., London.

Pimentel, D., Hepperly, P., Hanson, J., Douds, D., and Seidel, R. (2005), Environmental, energetic, and economic comparisons of organic and conventional farming systems, BioScience 55 (7), pp. 573-582.
Pimentel, D. and Pimentel, M. (2008), Food, Energy, and Society, CRC Press, Boca Raton, FL.

Pretty, J. (2008), Agricultural sustainability: concepts, principles and evidence, Philosophical Transactions of the Royal Society B 363 (1491), pp. 447-465.

Pretty, J. and Waibel, H. (2005), Paying the price: the full cost of pesticides, The Pesticide Detox: Towards a More Sustainable Agriculture, Pretty, J. (Ed.), Earthscan Publications, Ltd., London, pp. 39-54.

Rosegrant, M.W. and Cline, S.A. (2003), Global food security: challenges and policies, Science 302 (5652), pp. 1917-1919.

Rosset, P.M. (2000), Cuba: a successful case study of sustainable agriculture, Hungry For Profit : The Agribusiness Threat to Farmers, Food, and the Environment, Magdoff, F., Foster, J.B. and Buttel, F.H. (Eds.), Monthly Review Press, New York, NY, pp. 203-213.

Sassi, . (2006), Strategies for Sustainable Architecture, Taylor and Francis, New York, NY, pp. 44-49.

Selfa, T., Jussaume Jr., R.A., and Winter, M. (2008), Envisioning agricultural sustainability from field to plate: comparing producer and consumer attitudes and practices toward 'environmentally friendly' food and farming in Washington State, USA, Journal of Rural Studies 24 (3), pp. 262-276.

Sim,S., Barry, M., Clift, R., and Cowell, S.J. (2007), The relative importance of transport in determining an appropriate sustainability strategy for food sourcing, The International Journal of Life Cycle Assessment 12 (6), pp. 422-431.

Thrupp, L.A. (2000), Linking agricultural biodiversity and food security: the valuable role of agrobiodiveristy for sustainable agriculture, International Affairs 76 (2), pp. 265-281.

Weis, A.J. (2007), The Global Food Economy: The Battle for the Future of Farming, Zed Books, New York, NY, p. 29.

United Nations, Department of Economic and Social Affairs, Population Division (2009), World population prospects: the 2008 revision, highlights, working paper no. E S A / P / W P. 210, a v a i 1 a b l e a t : http://www.un.org/esa/population/publications/wpp20 08/wpp2008_highlights.pdf(accessed 5 August 2009). 
Caroline C. Krejci is a predoctoral research assistant in the Department of Industrial and Systems Engineering at the University of Washington. She received an M.S. in Industrial Engineering from Purdue University and a B.S. in Industrial Engineering from Bradley University. She has worked as an operations engineer for Lutron Electronics and United Parcel Service.

Benita M. Beamon is an Associate Professor of Industrial and Systems Engineering at the University of Washington. She holds a Ph.D. in Industrial and Systems Engineering from Georgia Tech, with an emphasis in production, distribution, and material handling and a minor in Environmental Policy. She received an M.S. in Operations Research from Cornell University and a B.S. in Industrial Engineering and Management Sciences from Northwestern University. Her primary research applications lie in the areas of sustainable supply chain management and humanitarian relief. She has worked as a project engineer for Rosemount, Inc., the RAND Corporation, and Merck, and has led research projects for LensCrafters, Hudson Specialty Foods, Medtronics, Flow International Corporation, the United Way, and the National Science Foundation. She currently serves on the editorial board of the International Journal of Modeling and Simulation. 